\title{
Impactos da seca na saúde mental de moradores de uma comunidade rural
}

Impactos de la sequía en la salud mental de los habitantes de una comunidad rural

Impact of drought on the mental health of residents of a rural community

Verônica Morais Ximenes

Universidade Federal do Ceará - Fortaleza - Brasil

Carla Evelline de Sousa Camurça

Universidade Federal do Ceará - Fortaleza - Brasil

Larissa Eufrásio Peixoto Mota

Escola de Saúde Pública do Estado do Ceará-Fortaleza - Brasil

Lívia Lima Gurgel

Universidade do Estado do Rio de Janeiro - Rio de Janeiro - Brasil

Jáder Ferreira Leite

Universidade Federal do Rio Grande do Norte - Rio Grande do Norte - Brasil

\section{RESUMO}

O presente artigo analisou os impactos da seca na saúde mental de moradores de uma comunidade rural do Ceará. O objetivo é analisar os impactos da seca na saúde mental de moradores da comunidade de Canafístula, localizada na zona rural de Apuiarés (Ceará). As metodologias quantitativa e qualitativa constituíram o desenho metodológico. Participaram do estudo 175 moradores, com idade entre 18 a 88 anos. Foram aplicados a Escala de Influências da Seca e a Escala de Saúde Mental-SRQ-20. Na etapa qualitativa foram realizados três grupos focais e seis entrevistas em profundidade. Os resultados apontaram que na Escala de Influências da Seca 100\% dos participantes ou sua família vivenciaram alguma seca. O SRQ-20 apontou a prevalência de transtorno mental comum de 36\% (63 pessoas) com prevalência de 84,5\% (49) para as mulheres. Os relatos dos participantes destacaram que a realidade da seca traz impactos para a saúde mental, pois afeta suas atividades produtivas, gera sentimentos de tristeza, insegurança quanto ao futuro e desânimo. Algumas políticas públicas como a construção de cisternas e as aposentadorias contribuem para enfrentar essa situação.

Palavras-chave: Seca. Saúde Mental. Comunidade rural. 


\title{
RESUMEN
}

El presente artículo analizó los impactos de la sequía en la salud mental de los habitantes de una comunidad rural de Ceará. El objetivo es analizar los impactos de la sequía en la salud mental de los habitantes de la comunidad de Canafístula, en la zona rural de Apuiarés (Ceará). Las metodologías cuantitativa y cualitativa constituyeron el diseño metodológico. Participaron del estudio 175 habitantes, con edad entre 18 a 88 años. Se aplicaron a la Escala de Influencias de la Seca y la Escala de Salud Mental-SRQ-20. En la etapa cualitativa se realizaron 3 grupos focales y 6 entrevistas en profundidad. Los resultados apuntaron que en la Escala de Influencias de la Seca, que el 100\% de los participantes o su familia experimentaron alguna sequía. El SRQ-20 apuntó la prevalencia de trastorno mental común del 36\% (63 personas) con prevalencia del 84,5\% (49) para las mujeres. Los relatos de los participantes destacaron que la realidad de la sequía trae impactos para la salud mental, pues afecta sus actividades productivas, genera sentimientos de tristeza, inseguridad en cuanto al futuro y desánimo. Algunas políticas públicas con la construcción de cisternas y las jubilaciones contribuyen a enfrentar esta situación.

Palabras clave: Sequía; salud mental; comunidad rural.

\begin{abstract}
This article analyzes the impacts of drought on the mental health of residents of a rural community in Ceará. The objective is to analyze the impacts of drought on the mental health of residents of the community of Canafístula, located in the rural area of Apuiarés (Ceará). The quantitative and qualitative methodology constituted the methodological design. A total of 175 residents, aged 18 to 88 years, participated in the study. The Drought Influence Scale and the SRQ-20 Mental Health Scale were applied. At the qualitative stage, 3 focus groups and 6 in-depth interviews were conducted. The results indicated that in the Drought Influence Scale, that $100 \%$ of participants or their family experienced some drought. SRQ-20 reported the prevalence of a common mental disorder of $36 \%$ (63 people) with a prevalence of $84.5 \%$ (49) for women. The participants' reports highlighted that the reality of drought impacts on mental health, as it affects their productive activities, generates feelings of sadness, insecurity about the future and discouragement. Some public policies with the construction of cisterns and pensions contribute to this situation.
\end{abstract}

Keywords: Drought. Mental Health. Rural community.

\section{Introdução}

Há estudos direcionados para os ambientes rurais em seus aspectos econômicos, produtivos e sociais, porém, ainda são poucos os que versam sobre o desenvolvimento e a vivência da subjetividade nesses contextos (Vasquez, 2009). No entanto, já é possível perceber uma preocupação por parte da Psicologia Social em pesquisar os modos de vida desta população e refletir sobre as formas de subjetividade nos contextos rurais (Albuquerque, 2002; Domingues, 2007; Leite, Macedo, Dimenstein \& Dantas, 2013).
As questões rurais perpassam desde a produtividade, passando pela definição de agricultura familiar, sustentabilidade, agroecologia, histórico das lutas e movimentos sociais, violência no campo e conflitos agrários e fundiários, perfil dos assentados, cultura, linguagem, modo de vida, costumes e redes de relações sociais nos assentamentos, chegando à importância da reforma agrária (Vasquez, 2009, p. 859).

Sawaia (2005) refere que o Brasil é constituído a partir de processos de exclusão/inclusão social perversos, sendo esse 
processo complexo e multifacetado. No cenário rural nordestino, pode-se perceber essa realidade através da compreensão do histórico de colonização com base na exploração dos recursos naturais e da força de trabalho do povo, aliado a processos sociais e políticos vinculados ao poder centralizador das oligarquias, do coronelismo e da profunda concentração fundiária.

Dessa forma, a vivência com a seca e seus impactos no modo de vida necessitam ser percebidos a partir da desigualdade social, da exclusão e da pobreza, bem como através das políticas públicas de desenvolvimento rural, que amenizam a situação de vulnerabilidade social, porém não retira as pessoas da situação de pobreza. A seca é um fenômeno natural e físico que ocorre frequentemente e com certa regularidade na região Nordeste, podendo se repetir de oito a dez vezes em um século, chegando a se estender por até cinco anos, causando problemas de natureza social e política (Duarte, 1999). A seca é um fenômeno natural, posto que se dá em decorrência da própria localização geográfica nordestina, mas seus impactos nocivos no modo de vida da população são de ordem social, tendo em vista que são os aspectos históricos, econômicos, políticos, culturais e ambientais compartilhados no território nordestino que contribuem para o agravo das consequências psicossociais da seca na saúde da população que vive em comunidades rurais.

\section{A seca no contexto rural do Nordeste brasileiro}

O sertão nordestino foi caracterizado de forma crítica por Castro (1984) que retratou a geografia alimentar do nosso país. Para esse autor, o sertão do Nordeste é caracterizado por possuir grandes latifúndios e desenvolveu sua formação econômico-social com base no modelo do coronelismo, através da pecuária, da agricultura de subsistência e do pastoreio nas terras secas distantes do litoral, cujo clima característico é o Semiárido.
Em 2011, o censo do Instituto Brasileiro de Geografia e Estatística (IBGE, 2011) apresentou dados de que no Brasil existem 16,2 milhões de pessoas vivendo em extrema pobreza e que $59 \%$ destas pessoas estão na região Nordeste. Desse percentual, $52 \%$ encontram-se na zona rural, dado preocupante, já que a pobreza nesta região historicamente foi relacionada à problemática da seca.

No Brasil, assim como no Nordeste, a pobreza rural se distingue da pobreza urbana. Ao problematizar essa pobreza rural, é importante afirmar que nossa compreensão desse fenômeno se dá partir da perspectiva multidimensional, especificamente da Abordagem das Capacitações (Sen, 2000) que compreende a pobreza a partir das privações as quais os sujeitos vivenciam e que os impedem do exercício de suas liberdades. Neste sentido, abrange a pobreza para além de questões econômicas, incluindo aspectos da renda, da habitação, dos principais bens de consumo, mas principalmente das relações sociais, do padrão de vida, do acesso à educação e à saúde.

A pobreza rural no Brasil corresponde ao processo desordenado da industrialização e urbanização do país desde o século XX, que embora tenha ocorrido certa expansão econômica, os resultados sociais do desenvolvimento vêm seguindo a lógica de acumulação de capital e por isso, continua produzindo altos índices de pobreza (Maluf \& Mattei, 2011). No Nordeste, a pobreza rural está relacionada com a desigualdade social no acesso à terra, à água e pela dificuldade que as comunidades rurais têm com relação às políticas públicas centradas na perspectiva de combate à seca. O baixo nível de escolaridade das pessoas é outro fator predominante para acentuar a pobreza rural. Há deficiências na infraestrutura no que diz respeito ao acesso à água potável, habitação, saneamento básico, transporte, lazer, cultura, saúde e educação. Embora a agricultura não seja a única atividade econômica existente no meio rural nordestino, tendo em vista que o fenômeno da 
seca dificulta as famílias agrícolas a sobreviverem através de sua produção, percebendo-se alto os níveis de desemprego.

Em decorrência da seca, o cotidiano da população da zona rural nordestina tem sido potencialmente afetado com as perdas na agricultura e com a falta de abastecimento de água, levando, muitas vezes, os pequenos proprietários a se desfazerem de sua terra na necessidade de sobreviver. A família sem-terra durante muito tempo precisou migrar para outros locais e viver à custa da caridade do dono da terra. Outra solução era partir para as grandes cidades em busca de oportunidade. Os que permanecem no campo assistem à morte de seus animais por sede e fome. $\mathrm{Na}$ impossibilidade de um emprego, somente lhes restam as medidas emergenciais oferecidas pelos governos.

Entre essas ações emergenciais oferecidas pelo Estado, estão a operação carropipa, construção de cisternas, perfuração e recuperação de poços, bolsa estiagem, venda de milho, programa garantia-safra e ampliação da linha de crédito emergencial, assim como renegociação de dívidas (Brasil, 2013). No entanto, essas ações não modificam a estrutura socioeconômica e política, da mesma forma que não retiram as pessoas do nível de vulnerabilidade social e da condição de miséria.

Por sua vez, nos últimos anos, tem-se intensificado a presença de políticas públicas e programas mais estruturados no meio rural brasileiro que têm amenizado alguns impactos da seca, a exemplo do Programa Luz para Todos, Programa Bolsa Família, previdência rural (Favareto \& Seifer, 2012), fortalecimento do PRONAF (Programa Nacional de Agricultura Familiar) e criação de programas de convivência com o semiárido, baseado em modelos agroecológicos.

Em um estudo relacionando as mudanças climáticas e a pobreza, Bruna e Pisani (2010) elaboraram um ciclo de risco para acidentes naturais em que as mudanças climáticas impactam sobre as populações pobres aumentando e agravando a situação de pobreza e a vulnerabilidade das populações que vivem esta realidade, tendo em vista que são as que mais sofrem com os acidentes naturais, formando um ciclo que se repete se não houver planejamento.

Segundo Mattedi e Butzke (2001), as calamidades naturais, entre elas a seca, trazem destruição, mas, ao mesmo tempo, permitem que as relações entre sociedade e natureza sejam repensadas. Apesar de causarem impactos há muito tempo, essas calamidades naturais continuam sendo pouco estudadas no Brasil. Sendo a seca um evento ocasionado por mudança climática, percebe-se que é importante realizar um estudo mais aprofundado com relação às suas implicações psicossociais, vislumbrando medidas preventivas de minimização de riscos psicossociais, pois a seca é um evento que potencializa a situação de vulnerabilidade social, ao estar associado às perdas financeiras, materiais e de recursos naturais (Favero, 2012).

\section{Impactos da seca na saúde mental}

Segundo a Organização Mundial da Saúde (OMS), a saúde mental "[...] é o estado de bem-estar no qual o indivíduo realiza suas próprias habilidades, pode enfrentar normalmente o estresse da vida, trabalhar produtivamente e contribuir para sua comunidade." (WORLD HEALTH ORGANIZATION, 2001, p. 1). O processo saúde-doença é, para além de questões biológicas, uma questão social dinâmica, complexa e multidimensional. Em 2005, a OMS criou a Comissão sobre Determinantes Sociais da Saúde (CDSS) com o objetivo de gerar reflexão e tomada de consciência sobre as "dimensões biológicas, psicológicas, sociais, culturais, econômicas, ambientais, políticas que se inter-relacionam quando se trata de saúde e doença de uma pessoa, de um grupo social ou sociedade" (Cruz, 2011, p. 28).

Os determinantes sociais de saúde apontam tanto para características 
específicas do contexto social que afetam a saúde, como para a maneira com que as condições sociais traduzem esse impacto sobre a saúde. Os determinantes sociais de saúde que merecem a atenção são aqueles que podem ser potencialmente alterados pela ação baseada em informações (CNDSS, 2008, p. 4).

O desafio permanente do Sistema Único de Saúde (SUS) é de garantir a promoção da saúde e a qualidade de vida de todos os cidadãos brasileiros, através de suas ações e serviços, reduzindo condições persistentes de vulnerabilidade e desigualdade social que certos grupos populacionais estão inseridos e como consequência resulta em Determinantes Sociais da Saúde (Brasil, 2012).

Siqueira e Morais (2009) afirmam que as mudanças climáticas que causam degradação ao meio ambiente têm relação direta com os comprometimentos na saúde física, nos transtornos psicológicos e psiquiátricos, assim como na desintegração social. As patologias tais como doenças infecciosas, degenerativas, cardiovasculares, neoplasias, crises de ansiedade e depressão, síndrome do pânico, dependência química e agravamento da violência, dentre outras, podem ter relação com os efeitos de fenômenos naturais no meio ambiente.

Há três mecanismos pelos quais os eventos climáticos podem afetar a saúde da população, quais sejam:

Efeitos diretos dos eventos climáticos extremos: Estes afetam a saúde através de influências sobre a fisiologia humana (por exemplo, ondas de calor) ou provocando traumas físicos e psicológicos em acidentes, como em tempestades, inundações e secas.

Efeitos sobre o meio ambiente, alterando fatores determinantes da saúde humana. Exemplos mais relevantes são efeitos do clima afetando a produção de alimentos, a qualidade da água e do ar e a ecologia de vetores (por exemplo, mosquitos) de agentes infecciosos.

Efeitos dos eventos climáticos sobre os processos sociais, determinando rupturas socioeconômicas, culturais e demográficas importantes. Um exemplo é a migração de grupos populacionais, desencadeada por secas prolongadas, que afetam principalmente populações que dependem da agricultura de subsistência (Confalonieri; Menne, 2007 citado por Confalonieri \& Marinho, 2007, p. 50).

Há pesquisas que consideram diferentes contextos no estudo da seca e, apesar disso, trazem resultados semelhantes. Estudos realizados na Austrália em torno de suas variações climáticas extremas apontaram como o fenômeno da seca, aliado a transformações socioeconômicas que vêm ocorrendo no meio rural, pode representar um risco à saúde pública e afetar o bem-estar e a saúde mental de seus habitantes (McMichael, 2011). Tanto grupos de fazendeiros mais velhos quanto de jovens sentem os impactos da seca em termos de estresse e de implicações em sua saúde mental, consideradas as especificidades desses grupos (Polain, Berry \& Hoskin, 2011).

Na região sul do Brasil, Favero (2012, p.27) refere que esse fenômeno é um "desastre importante do ponto de vista psicossocial". As comunidades rurais são as mais vulneráveis a esses impactos, já que dependem em sua maioria dos recursos naturais e com a seca os moradores são expostos a um alto nível de estresse, afetando assim a saúde psicológica. Silva, Dimenstein e Leite (2014) acrescentam que a população rural sofre com maior frequência as privações no que diz respeito às políticas de saúde pública, em especial as ações e programas de atenção primária e de saúde mental. Embora exista a Política Nacional de Saúde Integral da População do Campo e Floresta (PNSIPCF), em que o objetivo é "contribuir para a melhoria da 
qualidade de vida das populações do campo e da floresta, [...] envolvendo ações de saneamento e meio ambiente, especialmente para a redução de riscos sobre a saúde humana" (Brasil, 2011, p.5), essa política se configura como ainda um desafio tanto para a atenção psicossocial, quanto para a saúde pública em geral.

Neste sentido, refletir sobre os desdobramentos dos impactos provocados pela seca na economia, na política, nas instituições e no meio ambiente, é de fundamental importância, porém, devemos também nos voltar ao estudo das implicações psicossociais da seca no desenvolvimento da saúde mental, buscando compreender a realidade psicossocial dos sujeitos que vivenciam a desigualdade, a exclusão e a pobreza.

O presente artigo surge a partir de dados da pesquisa intitulada "Impactos da Pobreza no desenvolvimento da saúde comunitária: a avaliação psicossocial das comunidades do Bom Jardim (Fortaleza) e da Canafístula (Apuiarés/Ceará)", que apontou para a necessidade de aprofundar questões relacionadas ao impacto da seca na saúde mental dos moradores das comunidades. Desse modo, o objetivo deste estudo é analisar os impactos da seca na saúde mental de moradores da comunidade de Canafístula, localizada na zona rural de Apuiarés (Ceará).

\section{Método}

Os participantes foram selecionados a partir dos seguintes critérios: morar há mais de um ano no bairro; ter passado por alguma experiência com a seca; ter idade mínima de 18 anos - para poder se responsabilizar pelos depoimentos e declarar sua anuência ao estudo após ciência do termo de consentimento e demais informações sobre a pesquisa.

A amostra foi constituída por 175 participantes, tendo um total de $58 \%$ de mulheres. No que diz respeito à idade, esta variou de 18 a 88 anos. Entre essas pessoas, $65,4 \%$ afirmaram ser beneficiárias de programa de transferência de renda, notadamente o Bolsa Família. Para 56,5\% dos participantes, a renda familiar se concentrou em um a dois salários mínimos e menos de um salário mínimo para $27,1 \%$. No tocante à escolaridade, $30 \%$ tem ensino médio ou superior e $30,9 \%$ possuem ensino fundamental incompleto.

A comunidade investigada está localizada a $26 \mathrm{~km}$ de distância da sede do município de Apuiarés e 118 km de Fortaleza (Ceará). Vivem na comunidade em torno de 170 famílias, no total de pouco mais de mil pessoas. A renda local provém da agricultura familiar, benefícios sociais, funcionalismo público e aposentadorias. Com relação às características ambientais, seu clima é semiárido e a região sofre com o fenômeno da seca. A vegetação é típica do bioma caatinga, sua pluviosidade $(\mathrm{mm})$ é de 763,1 , com temperatura média de $26^{\circ}$ a $28^{\circ}$ e seu período chuvoso é de fevereiro a abril (IPEECE, 2013).

$\mathrm{Na}$ etapa quantitativa do estudo foram utilizados dois instrumentos: a) o Questionário de Influências da Seca, adaptado a partir de um conjunto de itens utilizados para descrever a experiência da seca no Questionário sobre Impactos Psicossociais da Seca (Favero, 2012). A primeira questão perguntava se a pessoa entrevistada ou sua família já passaram por alguma seca, portanto, as seguintes questões só foram respondidas por aquelas pessoas que afirmaram positivamente para a vivência de uma estiagem; b) A Escala de Saúde Mental - Self Report Questionnaire (SRQ-20), versão adaptada para o Brasil de Mari e Williams (1986). O instrumento é autoaplicável e contém escalas dicotômicas com respostas referentes a sim ou não, nas dimensões relacionadas a Pensamentos Depressivos, Sintomas Somáticos, Diminuição de Energia e Humor depressivo-ansioso e que devem ser respondidas a perguntas referentes a acontecimentos de, no máximo, 30 dias passados. As orientações seguidas na realização desta pesquisa, no entanto, foi a indicada por Gonçalves, Stein e Kapczinski (2008), os quais entendem que o SRQ-20 é um 
instrumento de rastreamento de transtornos não psicóticos, portanto não de diagnóstico. $\mathrm{Na}$ etapa qualitativa, foram realizados três Grupos Focais (GF) e seis entrevistas em profundidade com pessoas que já haviam participado da pesquisa quantitativa, através de perguntas norteadoras sobre as categorias saúde mental e seca.

Os dados quantitativos foram organizados através do pacote estatístico SPSS 20.0 e suas análises foram realizadas com base no referencial teórico adotado. Os dados qualitativos foram transcritos e analisados a partir das categorias com o auxílio do software Atlas.ti 5.2. A pesquisa foi submetida ao Comitê de Ética em Pesquisa de uma Instituição de Ensino Superior, por meio de sistema da Plataforma Brasil e foi aprovado com CAAE: 07810512.3.0000.5054 e Parecer $\mathrm{N}^{\circ} 191.508$.

\section{Resultados e Discussões}

\section{A vivência da seca}

No Questionário de Influências da Seca, ao serem indagados sobre a vivência da seca, das 175 pessoas entrevistadas, todas responderam afirmativamente que elas ou sua família já passaram por alguma seca. Nos relatos a seguir, identificamos o modo de vida impactado pela seca. Para Guimarães, a seca ocorre "porque não chove, não choveu aí é seco, né?". No discurso de Cícero, a seca ocorre "quando não há inverno, sabe, quando não há inverno pra fazer a gente comer... a seca que nóis chama é essa. Seca né? é que não há chuva pra fazer legume ai é seca, né?". Na percepção de Severina, o período atual em que estamos vivendo é de seca, "que num tem um inverno, que falta a chuva. Aí falta a chuva, falta tudo. Falta a comida pro bicho, falta o plantio que a gente planta, os legume, né?".

O determinismo geográfico nordestino fundamenta o discurso da seca e a associação de que a natureza é a única responsável pela miséria que atinge a região. Percebemos que a fala de Inácia transmite essa condição naturalizante do fenômeno da seca: "Num sei, acho que as coisa da natureza mesmo. Sei não, disso daí não sei explicar não [...] Eu acho que... sei não, a seca é coisa da natureza!". Carvalho (1988) e Castro (1992) mostram que o discurso sobre a naturalização dos problemas sociais causados pela seca está ligado a estratégias das oligarquias regionais na manutenção do poder e da riqueza.

Com isso, percebemos que esse fenômeno incidiu sobre a necessidade de $63,4 \%$ dos participantes, que em algum momento necessitaram modificar planos ou projetos em função de uma seca, o que levou $46,6 \%$ das pessoas ao endividamento. Com relação aos impactos sociais, $39,1 \%$ dos entrevistados tiveram a saída do campo para a cidade de algum membro da família, enquanto que $13,1 \%$ tiveram a saída de algum membro da família da escola.

Pra fazer a vazante nóis fazia um empréstimo, sabe? Com governo, esse empréstimo vinha num sei da onde, pra nóis comprar uma roda, motor, essas coisa né... aí quando a gente terminava de colher tinha que tirar o dinheiro pra pagar aquele empréstimo, sabe? Aí o que sobrava é o que a gente ia comer. Era assim! (Cícero, Entrevista).

Dentre os impactos econômicos observados como relevantes para a maioria das pessoas foram encontrados: 41,1 \% dos entrevistados já experimentaram a falta de água para o consumo humano, 54,3\% a falta de água para o consumo animal e 93,1\% perdas na produção. Nos grupos focais, os moradores destacaram a falta de água e as dificuldades encontradas para continuar com a criação de animais:

Uma seca, ela desanima muito o pequeno agricultor... a seca pra nós $e ́$, sinceramente, um prejuízo enorme e a gente não consegue às vezes nem enxergar... a gente vai ter a falta d'água, a gente vai ter a falta do 
criar, porque não tem a ração da criação e a gente não tem condição de comprar ração pra criar os animais (GF 2).

Agora fica ruim assim, pro fazendeiro, por que ele vai se bater em pasto, pra que? Pra dá conta daqueles animais dele pra não deixar morrer de fome, vou dizer, por que é isso é só o pior que tem, por que aí não tem governo que dê pra proteger... o maior problema hoje da seca é a falta de água e o alimento dos animais é o maior problema que tem por que, por que falta água pra beber, falta água pros animais, $e$ falta comer. É o pior problema são esses. (GF 2)

Do ponto de vista das implicações psicológicas da seca, os principais aspectos relacionados foram insegurança quanto ao futuro $(79,3 \%)$ e sentimentos de desânimo e tristeza $(82,8 \%)$.

O теи pai, você sabe que o теи pai é agricultor. E na época dessa época de estiagem ele fica emocionamente, ele fica uma pessoa triste, desanimado. Então quando começa a chover, por pouco que seja, já é uma coisa assim que a gente já ver que ele muda sabe. Então pra nós aqui, que moramos na zona rural aqui em Canafístula, é um problema sério". (GF 2)

Favero (2012) identificou prejuízos no bem-estar e na saúde psicológica da população que vivencia a realidade da seca, e com isso há "alteração na rotina familiar, a redução nas atividades de lazer, prejuízos no sono, aborrecimento, preocupação, dificuldades de higiene, sentimentos de desânimo, tristeza, impotência e insegurança quanto ao futuro" (Favero, 2012, p. 103).

Por outro lado, os moradores também afirmam a existência de projetos do Governo que trabalham com a prevenção da seca, como a construção de cisternas na comunidade, minimizando seu impacto:

(...) A nossa cisterna já encheu, tá certo que é pequena, mas dá pra tirar o verão todinho dependendo do verão né? Se for um verão normal até dezembro dá pra tirar, aí quando vem uma chuva eu fico quase como doida, desesperada, é com o tambor aparando água e o tambor secando e eu enchendo, a cisterna cheia (GF 3 ).

Esses projetos acabam por se configurar como estratégias de enfrentamento diante dos efeitos da seca, permitindo acesso mínimo à água e alimentos, como também alterando os significados dados a esse fenômeno em que o mesmo já não comparece com a dimensão aterrorizante de outras épocas.

A política pública relacionada à Seguridade Social, que possibilita a aposentadoria do trabalhador e trabalhadora rural, promove uma segurança para enfrentar a seca. Para Inácia, as pessoas que têm salário, são aposentadas ou recebem algum benefício do Governo Federal passam por uma seca de forma diferente de quem não tem uma renda. Para ela, "nossos problema da seca é a pessoa que cria, que fica mais preocupada com esses problema aí, não é? [...] se a pessoa tem o salário, ela veve daquele salário, não tem como se preocupar muito, né? Só se caso criar um bichim que fica preocupado"(Inácia, Entrevista). Essas considerações também são observadas em Helfand e Pereira (2012) ao assinalarem que o cenário da pobreza rural em nosso país se modificou, especialmente em função das políticas de transferência de renda e seguridade social, o que incitou o aumento da qualidade de vida das famílias do campo.

\section{Saúde mental}

Para os 175 participantes da pesquisa, a prevalência para Transtornos Mentais Comuns (TMC) estimada foi de $36 \%$ (63 pessoas). A proporção, segundo o sexo de prevalência para TMC, encontrada em nosso estudo foi de 
$84,5 \%$ (49) para o sexo feminino e de $15,5 \%$ (14) para o sexo masculino:

a saúde mental é você saber agir as coisas, até pra o convívio das pessoas e a doença mental, na mente, que é parado, num tem agilidade pra nada e a física é você poder se deslocar, executar todas as suas coisas que exige do corpo ne? Estrutura física (Rachel, Entrevista).

Segundo Moreira, Bandeira, Cardoso e Scalon (2011), a prevalência está de acordo com a encontrada em alguns estudos já realizados no Brasil, em que revelam a prevalência de $17 \%$ a $35 \%$. Para Moreira et al. (2011), a prevalência de TMC está associada ao baixo nível socioeconômico e a baixa escolaridade. Acrescentam, ainda, que há um maior risco de TMC para o sexo feminino e em pessoas adultas/idosas. Em uma investigação sobre a prevalência de TMC em trabalhadoras rurais de um assentamento de reforma agrária no Nordeste brasileiro, Costa, Dimenstein e Leite (2014) encontraram 43,6\% de suspeição diagnóstica para as mulheres. Pode-se constatar que os estudos trazem uma porcentagem condizente com a indicada por esta pesquisa e a prevalência de TMC em mulheres.

A Escala de SRQ-20 distribui seus itens em quatro dimensões: Pensamentos depressivos, Sintomas somáticos, Humor depressivo-ansioso e Diminuição de energia. $\mathrm{O}$ item com maior frequência de resposta positiva encontrada foi para a questão sobre se a pessoa se sente nervosa, tensa ou preocupada, presente na dimensão Humor depressivo-ansioso em que $63,4 \%$ dos participantes responderam sim a essa pergunta.

A pessoa entra em estado de depressão, de tristeza. Tem até a... Como é que a gente diz? ... estressado... fica estressado, muda... muda o visual da pessoa, com certeza, né? Então assim, se a pessoa tivesse... Não vou dizer tudo que quisesse, mas o necessário, sem ter dificuldade nenhuma, a vida das pessoas seria melhor, porque seria... Ia ter menos preocupação, né? Sua mente ia tá mais calma, mais... Como é que eu digo? Mais assim, com bom astral pra você... né? Viver. E é difícil mesmo, a pessoa passar por um momento difícil sem puder resolver, sem ter ajuda, sem ter um ombro amigo, sem ter nada... É difícil! (Severina, Entrevista).

$\mathrm{O}$ item com a segunda maior frequência de resposta positiva encontrada foi para a questão sobre se a pessoa tem dificuldades para tomar decisões, presente na dimensão Diminuição da energia, foi de 46,9\% responderam sim a essa pergunta. Diante das dificuldades financeiras advindas dos períodos da seca, há uma grande dificuldade em decidir qual o melhor caminho a seguir, já que a situação da falta de água, de alimentos, morte dos animais e perda da produção propiciam um cenário de difícil convivência e sem perspectivas. No seguinte relato há a constatação disso: "Faz pra melhor? Não... a gente tem que aguentar assim. A gente não tem nada a fazer, né? Tem que aguentar mesmo. Levar do jeito que der certo, né?" (Guimarães, Entrevista).

Santos (2006) refere que os estudos que utilizam o SRQ-20 no Brasil devem considerar a realidade local, tendo em vista a diversidade das regiões brasileiras. No caso do nordeste, os aspectos sociodemográficos apresentam como um fator importante de diferenciação para a detecção dos TMC.

Percebe-se, através da fala dos participantes dos grupos focais, que a falta de chuva, que tem como consequência a seca dos açudes, traz desânimo para as pessoas e uma sensação de insegurança, que pode ser evidenciada na fala de uma das moradoras de Canafístula: "Tá muito bom porque começou a chover né? Mas tava muito desanimado porque o nosso açude... pra nós todos, tá secando... O que é que vai ser da gente né?" (GF 2). Uma das participantes de um dos grupos focais relata também sobre a principal dificuldade enfrentada pelos moradores no 
período da seca, destacando também os sentimentos de desânimo e tristeza que a seca traz:

Pra cá pra Canafístula, pra nossa comunidade, eu acho que a dificuldade maior é a questão da água... O meu pai, você sabe que o meu pai é agricultor. E na época dessa época de estiagem ele fica emocionalmente, ele fica uma pessoa triste, desanimado. Então quando começa a chover, por pouco que seja já é uma coisa assim que a gente já ver que ele muda sabe. Então pra nós aqui que moramos na zona rural, aqui em Canafístula é um problema sério (GF 2).

A população sofre com a escassez de água e o povo nordestino suplica a Deus por chuva, para, assim, acabar com o sofrimento. A seca, então, é associada à religiosidade, que é um elemento da vida dos nordestinos (Vieira Jr., 2003) e surge como alento único nos momentos difíceis. Inácia revela um discurso de resignação diante dos efeitos sociais decorrentes da seca, pois, para ela, "Assim... se for do jeito que tá tendo mesmo é coisa de Deus mesmo, né? A gente num tem... num pode fazer nada a respeito dessas coisa assim" (Inácia, Entrevista). Sendo assim, também percebemos que o fenômeno relacionado ao modo como as pessoas vivenciam a situação de pobreza e dificuldade no contexto rural chamado de fatalismo ou síndrome fatalista (Martin-Baró, 1998). O fatalismo é uma categoria psicológica que anuncia o modo de funcionar do psiquismo, em que o presente e o futuro são percebidos como predeterminados, fazendo com que os sujeitos aceitem os acontecimentos passivamente, sem questionamentos ou inquietações. $\mathrm{O}$ sentimento fatalista pode ser analisado com uma forma de conformismo que aponta somente Deus como responsável pelo milagre da chuva, como também, uma forma de enfrentamento para poder conviver com uma realidade tão dura e opressora.
Segundo Ximenes e Camurça (2016), há muitas dificuldades relacionadas ao acesso por parte dos moradores e das moradoras rurais aos serviços de atenção psicossocial, principalmente nos Centros de Atenção Psicossocial (CAPS), que estão localizados na sede dos municípios e somente um por município. Silva et al (2014) também relatam esse cenário de dificuldade na prevenção e tratamento da saúde mental.

\section{Considerações finais}

É provável, portanto, que a situação da seca traga para os moradores de Canafístula um sofrimento que vai além do físico e da falta de recursos, impactando sobre a saúde mental desses moradores, na medida em que interfere no estado de ânimo e no sentimento de segurança. Diante das relações existentes entre a seca e a saúde mental, identifica-se que, no contexto rural do Nordeste e da comunidade da Canafístula, a seca está presente na vida das pessoas. Não se pode analisar a seca somente do ponto de vista dos efeitos climáticos, mas incorporar outros aspectos relacionados à vida do nordestino, como a saúde mental. Então essas análises utilizam uma visão multidimensional para tratar os problemas da seca.

As implicações da seca na saúde mental ficaram evidentes nos problemas associados à insegurança quanto ao futuro, sentimentos de desânimo e tristeza. Como também, a análise de prevalência de transtornos mentais que foi encontrada no limite superior dos estudos realizados no Brasil com maior prevalência em mulheres. Essa prevalência de TMC tem relação com os múltiplos papéis que elas desempenham na Comunidade da Canafístula, como: trabalhadora rural, bordadeira, costureira mãe, filha, esposa, chefe de família, líder comunitária e outros. A importância de estudos sobre a saúde mental nos contextos rurais ainda é um tema pouco abordado, porém de suprema relevância para compreensão da qualidade de vida desses moradores. 
A vivência da seca pelos moradores traz uma série de privações que são diferentes das vivenciadas em outras épocas, quando não havia políticas públicas voltadas para essa problemática. Apesar dessa realidade de privação ainda ser presente nas suas vidas, percebe-se a partir dos dados, que também existem novas perspectivas frente ao fenômeno da seca e novas formas de enfrentamento. $\mathrm{O}$ risco de se passar fome durante a ocorrência desse fenômeno não é mais tão constante como em outras épocas, assim como também há mais apoio governamental, que visa amenizar os impactos provenientes dessa realidade, como o programa Bolsa Família e outros. No entanto, diante das mudanças das leis trabalhistas e das políticas de Assistência Social que estão em curso no Brasil, não temos mais segurança da continuidade das políticas públicas relacionadas ao contexto rural.

Apesar de ações governamentais e estratégias de superação dos indivíduos da comunidade, os impactos desse fenômeno ainda são consideráveis, pois não se trata apenas de um fenômeno natural, visto que ele também é um problema social e político. Assim, é preciso pensar em formas de enfrentar essa seca não só enfatizando-a como uma mudança climática, mas sim, problematizando as questões sociais, percebendo as desigualdades existentes e os interesses políticos e econômicos por trás da indústria da seca. Ainda há um grande desconhecimento por parte das políticas públicas relacionadas à atenção psicossocial das influências do problema na seca na vida das pessoas que vivem no contexto rural, falta uma análise aprofundada da influência dos aspectos objetivos (seca) nos aspectos subjetivos (saúde mental).

\section{Referências}

Albuquerque, F. J. B. (2002). Psicologia

Social e formas de vida rural no Brasil. Psicologia: Teoria e Pesquisa, 18(1), 37-42. Recuperado de http://www.scielo.br/pdf/ptp/v18n1/a05v18 n1.pdf.

Brasil. Ministério da Saúde (2011). Política

Nacional de Saúde integral das Populações do Campo e da Floresta (PNSIPCF).

Brasília. Recuperado de http://bvsms.saude.gov.br/bvs/publicacoes/ politica_nacional_saude_populacoes_camp o.pdf.

Brasil. Ministério da Saúde. (2012). Política de promoção da equidade em saúde.

Secretaria de Gestão Estratégica e Participativa. Departamento de Apoio à Gestão Participativa. - Brasília: Ministério da Saúde. Recuperado de http://bvsms.saude.gov.br/bvs/saudelegis/g m/2011/prt2866_02_12_2011.html.

Brasil. (2013). Observatório de Enfrentamento à Seca. Recuperado de http://www.brasil.gov.br/observatoriodasec a/index.html.

Bruna, G. C., \& Pisani, M. A. J. (2010). Mudanças Climáticas e Pobreza: Reflexões. Revista Brasileira de Ciências Ambientais, 18, 58-66. Recuperado de http://abesdn.org.br/publicacoes/rbciamb/PDFs/1808_RBCIAMB-N18-Dez-2010Materia06_artigos261.pdf.

Carvalho, O. (1988). A economia política do Nordeste: seca, irrigação e desenvolvimento. Rio de Janeiro: Campus: ABID.

Castro, J. (1984). Geografia da Fome: o dilema brasileiro: pão ou aço. Rio de Janeiro: Edições Antares.

Castro, I. E. (1992). O mito da necessidade: discurso e prática do regionalismo nordestino. Rio de Janeiro: Bertrand Brasil.

CNDSS, Comissão Nacional sobre os Determinantes Sociais da Saúde (CNDSS). (2008). Relatório Final da Comissão Nacional sobre Determinantes Sociais da Saúde. As causas sociais das iniquidades em saúde no Brasil. Recuperado de http://bvsms.saude.gov.br/bvs/publicacoes/ causas_sociais_iniquidades.pdf.

Confalonieri, U. E. C; \& Marinho, D. (2007). Mudança climática global e saúde: perspectivas para o Brasil. 
Revista Multiciência, São Paulo, Mudanças Climáticas, 8, 49-64. Recuperado de http://www.multiciencia.unicamp.br/artigos 08/a_03_8.pdf.

Costa, M.; Dimenstein, M. \& Leite, J. (2014). Condições de vida, gênero e saúde mental entre trabalhadoras rurais assentadas. Estudos de Psicologia, 19(2), 145-154.

Cruz, M. M. (2011) Concepção de saúdedoença e o cuidado em saúde. In R. Gondim; V.Grabois, \& W. Mendes Junior (Orgs). Qualificação de gestores do SUS.

2a. Ed. Rio de Janeiro:

Fiocruz/EAD/ENSP.

Domingues, E. (2007). Vinte anos do MST: a psicologia nesta história. Psicologia em Estudo, 12(13), 573-582. Recuperado de http://www.readcube.com/articles/10.1590 \%2Fs1413-73722007000300014.

Duarte, R. (1999). A seca nordestinha de 1998-1999: da crise econômica a calamidade social. Recife: Sudene.

Favareto, A., \& Seifer, P. (2012). As diferentes formas de definir o rural brasileiro e algumas tendências recentes implicações para políticas de desenvolvimento e combate à pobreza. In Miranda, C., \& Tibúrcio, B. (Orgs), A nova cara da pobreza rural: desafios para as políticas públicas (pp. 55-106). Brasília: IICA. Recuperado de http://www.iicabr.iica.org.br/wpcontent/uploads/2014/03/DRS-16.pdf.

Favero, E. (2012). O impacto psicossocial das secas em agricultores familiares do Rio Grande do Sul: Um estudo na perspectiva da Psicologia dos Desastres. (Tese de Doutorado, Instituto de Psicologia, Universidade Federal do Rio Grande do Sul, Porto Alegre). Recuperado de https://www.lume.ufrgs.br/bitstream/handle $/ 10183 / 55063 / 000856224 . p d f$ ? sequence $=1$.

Gonçalves, D. M.; Stein, A. T.; \& Kapczinski, F. (2008). Avaliação de desempenho do Self-Reporting Questionnaire como instrumento de rastreamento psiquiátrico: um estudo comparativo com o Structured Clinical Interview for DSM-IV-TR. Cad. Saúde Pública, 24(2), 380-390. Recuperado de

http://www.scielo.br/pdf/csp/v24n2/16.pdf

Helfand, S.; \& Pereira, V. (2012).

Determinantes da pobreza rural e implicações para as políticas públicas no Brasil. In: C. Miranda \& B. Tibúrcio (Orgs). A nova cara da pobreza rural: desafios para as políticas públicas (pp.121159). Brasília: IICA. Recuperado de http://www.iicabr.iica.org.br/wpcontent/uploads/2014/03/S\%C3\%A9rieDRS-vol-17.pdf.

IBGE. Censo Demográfico 2010. (2011). Brasília: Ministério do Planejamento, Orçamento e Gestão.

IPEECE (2013) Perfil básico municipal 2013 Apuiarés. Fortaleza. Recuperado de http://www.ipece.ce.gov.br/publicacoes/per fil_basico/pbm-2013/Apuiares.pdf.

Leite, J.; Macedo, J.P.; Dimenstein, M., \& Dantas, C. (2013). A formação em Psicologia para atuação em contexto rural. In J. Leite \& M. Dimenstein

(Org.). Psicologia e contextos rurais (pp. 27-56). Natal: EDUFRN.

Maluf, R.; \& Mattei, L. (2011). Elementos para construção de uma agenda de políticas públicas para o enfrentamento da pobreza rural. In C. Miranda \& B. Tiburcio (Org). Pobreza Rural: concepções, determinantes e proposições para a construção de uma agenda de políticas públicas. Série Desenvolvimento Rural Sustentável: Edição Especial. Brasília: IICA. Recuperado de http://repiica.iica.int/DOCS/B2101P/B2101 P.PDF.

Mari, J., \& Williams, P. (1986). A validity study of a psychiatric screening questionnaire (SRQ-20) in primary care in the city of São Paulo. British Journal of Psychiatry, 148(JAN.), 23-26. doi: 10.1192/bjp.148.1.23

Mattedi, M. A., \& Butzke, I. C. (2001). A relação entre o social e o natural nas abordagens de hazards e de desastres. Ambiente e Sociedade, IV (9), 93-114. Recuperado de http://www.scielo.br/pdf/asoc/v4n9/16877. 
Martin-Baró, I. (1998). Psicología de la liberación. Madrid: Editorial Trotta.

McMichael, A. J. (2011). Drought, drying and mental health: Lessons from recent experiences for future risk-lessening policies. The Australian Journal of Rural Health, 19, 227-228. Recuperado de http://onlinelibrary.wiley.com/doi/10.1111/j .1440-1584.2011.01217.x/pdf.

Moreira, J. K. P., Bandeira, M., Cardoso, C. S., \& Scalon, J. D. (2011). Prevalência de transtornos mentais comuns e fatores associados em uma população assistida por equipes do Programa Saúde da Família. Jornal Brasileiro de Psiquiatria, Rio de Janeiro, 60(3), 221-226. Recuperado de

http://www.scielo.br/pdf/jbpsiq/v60n3/12.p $\underline{\mathrm{df}}$

Santos, O. B. S. (2006). Estresse ocupacional e saúde mental: desempenho de instrumento de avaliação em populações de trabalhadores na Bahia, Brasil.

(Dissertação de Mestrado, Universidade Estadual de Feira de Santana, Feira de Santana). Recuperado de: http://livros01.livrosgratis.com.br/cp04935 $\underline{0 . p d f}$

Sawaia, B. (2005). O sofrimento ético-político como categoria de análise da dialética exclusão/inclusão. In: B. Sawaia (Org.), As artimanhas da exclusão: uma análise ético psicossocial da desigualdade. (5). Ed. Petrópolis, RJ: Vozes, 2005, (pp. 97-119).

Sen, A. (2002). Desenvolvimento como liberdade. São Paulo: Companhia das Letras.

Siqueira, M. M. \& Morais, M. S. (2009). Saúde coletiva, resíduos sólidos urbanos e os catadores de lixo. Ciência \& Saúde Coletiva, 14(6), 2115-2122. Recuperado de https://dx.doi.org/10.1590/S141381232009000600018.

Vasquez, G.C.F. (2009). A psicologia na área rural: os assentamentos da reforma agrária e as mulheres assentadas. Psicologia, Ciência e Profissão, 29(4), p. 856-867, 2009. Recuperado de http://www.redalyc.org/articulo.oa?id=2820 21779015.
Vieira JR., A. (2003). O açoite da seca: família e migração no Ceará (1780-1850). Boletim de História Demográfica, São Paulo, 10 (27), 1-16. Recuperado de http://www.abep.nepo.unicamp.br/docs/ana is/pdf/2002/GT_His_ST4_Vieira_texto.pdf.

WHO, WORLD HEALTH ORGANIZATION (2001). Strengthening mental health promotion. Geneva: World Health Organization (Fact sheet, No. 220).

Ximenes, V., \& Camurça, C. (2016). Novos cenários da pobreza e da seca na zona rural nordestina: suas implicações na saúde mental. In M. Dimenstein; J. Leite; J. Macedo \& C. Dantas (Orgs.). Condições de vida e saúde mental em contextos rurais (pp. 175-194). Natal: UFRN.

Dados sobre os autores:

- Verônica Morais Ximenes é Doutora em Psicologia pela Universidade de Barcelona (UB) e Pós-doutora em Psicologia pela Universidade Federal do Rio Grande do Sul (UFRGS). Professora Associada da Graduação e Pós-Graduação em Psicologia do Departamento de Psicologia da Universidade Federal do Ceará (UFC). Bolsista de Produtividade em Pesquisa do CNPq PQ-2.

- Carla Evelline de Sousa Camurça é Mestre em Psicologia pela Universidade Federal do Ceará - UFC; Especialista em Caráter de Residência Multiprofissional em Saúde da Família, pela Escola de Formação em Saúde da Família Visconde de Sabóia (2007); Especialista em Saúde Mental pela Universidade Estadual do Ceará - UECE (2005).

- Larissa Eufrásio Peixoto Mota é graduada em Psicologia pela Universidade Federal do Ceará (2016). Tem experiência na área de Psicologia social, com ênfase em Psicologia Comunitária, e na área de Clínica Fenomenológica existencial. Integrante do Núcleo de Psicologia Comunitária (2012 2014) e bolsista de pesquisas PIBIC/UFC e PIBIC/CNPQ (2014-2016), realizando 
atividades de ensino, pesquisas e extensão voltados para o estudo, a problematização e o enfrentamento das iniquidades sociais. Participou da organização da Conferência Internacional de Psicologia Comunitária (2014). Experiência com grupos comunitários e terapêuticos assim como atendimentos individuais.

- Lívia Lima Gurgel é graduada em Psicologia pela Universidade Federal do Ceará. Mestranda no Programa de Pós-graduação em Psicologia Social da Universidade Estadual do Rio de Janeiro.

- Jáder Ferreira Leite possui Licenciatura Plena em Psicologia e Formação de psicólogo pela Universidade Estadual da Paraíba (1996 e 1998); mestrado em Psicologia pela Universidade Federal do Rio Grande do Norte (2003), doutorado em Psicologia Social pela UFRN (2008) e estágio pós-doutoral junto ao Núcleo de Psicologia Comunitária (NUCOM) da UFC (2014). É professor adjunto IV, vinculado ao Departamento de Psicologia da Universidade Federal do Rio Grande do Norte/RN. Presidente da Associação Brasileira de Psicologia Política (Gestão 2017 - 2018). Atua no campo da Psicologia social e política a partir dos temas: movimentos sociais e contextos rurais, relações de gênero, saúde mental e processos de subjetivação. 